\title{
WÖRTERBUCH
}

DER

\section{KLINISCHEN KUNSTAUSDRÜCKE.}

FƯR STUDIERENDE UND ÄRZTE.

\author{
VoN
}

Dr. MED. OTTO DORNBLÜTH,

DIREKTOR DER PROVINZIAL-PFLEGE-ANSTALT IN FREIBURG I. SCHL.

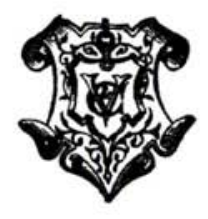

LEIPZIG,

VERLAG VON VEIT \& COMP.

1894. 
Unveränderter fotomechanischer Nachdruck

Walter de Gruyter GmbH \& Co. 1999

$$
\text { 章 } 25 \underbrace{1749}_{1999}
$$

Druck ron Metzger \& Wittig in Leipzig. 